\title{
Can certain actions in virtual space make a human being impatient?
}

\begin{abstract}
Nadine Touzeau
Department of Behavioral and Environmental Analysis, France
\end{abstract}

\author{
"Correspondence author \\ Nadine Touzeau \\ Department of Behavioral and Environmental Analysis, \\ France
}

Submitted : 17 Jan 2020 ; Published : 06 Feb 2020

\begin{abstract}
Summary: In 2005, Research Centre for the Study and Observation of Living Conditions noted that $62 \%$ of Internet users are trying to save time in preparing for their purchase. It is now $89 \%$ for online buyers [1].

In 2018, a survey carried out for the management of the Lemonde. fr site measured that after five seconds of waiting, out of ten potential readers behind the screen, three abandon [2].

According to the Baromil survey from 2018, because the information is available in real time, we are constantly connected in real time. Google, the most used search engine, does not even take 1 second to display thousands of results for our query, whatever it may be [3]. According to Jean Cottraux, psychiatrist and psychotherapist, we are faced with "a society that pushes buttons. We are constantly waiting for an immediate response" [4].

These few examples and with regard to my own research work on Behavioural Differentiations between the Real and the Virtual, my theories on "Avatarization", the "Transverse Zone" and the "Virtual Intelligence", developed in my scientific article and my books, impatience seems to have increased due to the use of the connected tool [5,6]. Behaviours have changed from that.
\end{abstract}

These behaviors can also be reproduced in the real world.

What about impatience? How is it characterized in the real and virtual?

Keywords: Net-Profiling, Impatience, Transverse Zone, Cyberspace, Virtual Space, Behavioral Differentiation, Avatarization, Virtual Intelligence

\section{Introduction}

It is identified that impatience has increased due to the fluidity of the use of information, from the rapid obtaining of anything on the Internet, even to purchases without moving with rapid delivery.

Ease our lives from anywhere as long as the connected tool is within reach, created Behavioral Differentiations, as my research has shown.

If these Behavioral Differentiations were also to increase or decrease some of our behaviors? Including impatience.

We know that these behaviors revealed or developed in the virtual can be reproduced in the real world. In fact, how does impatience position itself in both universes?

\section{Discussion}

Let's start by understand what impatience is. On the Wikipedia website, the definition of impatience is: "Lack of patience, feeling of anxiety or irritation that one experiences, either in the suffering of an evil, or in the expectation of some good".

These strong words emerge from this definition, which is shared by many dictionaries.

Waiting is the word that comes out first to me. Taking the time to wait seems to be a vain need in a society where everything is always going very fast. Optimizing your time to save more money is one of the leitmotifs of any businessman. Fulfill her days with necessary personal and professional tasks that mothers know how to finish and integrate well into their schedules.

It seems that things must go faster without taking the time to eat, to sit down and talk, to think, to take care of yourself.

The man with certain needs. Some of these acts will change behaviors, such as changing your diet to go as fast as possible, or even depriving yourself of food, sitting down to eat, chewing faster that can have an impact on the body, the stomach,...

Other needs will be felt such as the need to feed oneself intellectually, to spread one's pain with words on social networks, to relax... 
Always go faster to do more to accomplish daily tasks and finish the day exhausted. The connected tool is a godsend in order to optimize its time.

It can be used anywhere as long as it is connected to the Internet. A person with little time for himself will tend to use it constantly. To evacuate, enrich, communicate, inform himself... This involves endangering yourself sometimes by looking at your connected phone in the street, without realizing that you are crossing a street, your eyes fixed on the connected tool. This is in line with my scientific theory on the "Transverse Zone" [7].

The notion of time that I mentioned in one of my scientific publications no longer has the same reference points as when we were not working with connected tools [8].

Man has synchronized himself with this connected tool. He integrated it into his life and got used to the speed of the actions he obtained.

This connected tool brings in a few actions and time without moving from where you are quickly.

You can buy an ebook book integrated into your smartphone or tablet and read it just after the one-click purchase. So we search, find out, buy and consume in a short time and without moving from where we are.

This notion of speed is confirmed in other examples. Tel: I'm tired, I'm angry, I've had a good day, and I'm pouring out on social networks. In the toilets, at my desk, on public transport, on the street, in short, from anywhere I instantly evacuate my emotions, my aches, my sufferings, my feelings on the web.

These two examples cited are examples of impulsive actions without taking the step of either physically and geographically searching for the need to find and consume it, or, by evacuating one's emotions without thinking about the impacts and incidences of doing so on the web as if one were alone in one's bubble.

We do not wait in the same way as going to a shop that we have to find, on foot, with a vehicle or organized by public transport, as to be installed on our couch and have to find something to buy online and read immediately the book we were looking for.

Nor do we wait to see our therapist, best friend or parent to evacuate emotions that hurt us.

Almost everything can be done at à distance such as these examples: managing the material as well as your emotions. In a few clicks, sometimes in a few seconds. Without moving from where you are as long as you have the connected tool in your hand.

The Internet offers a number of facilities. Whether in choices, access, knowledge, discoveries, offers of sales and purchases, teaching, etc., it is important to be aware of the importance of these factors.

These facilities obtained in a short period of time, at any time, almost anywhere in the world depending on the management of Internet flow authorizations, unlike what happens in real life, and, without moving, are anchored in each user. It becomes a routine and an evidence.

To such an extent that if the Internet user is forced to wait too long to obtain information or a product, he changes his website. If the Internet user sees his or her tool connected taking too long to be connected to the Internet, he or she is stressed. If an answer to an SMS is delayed, again, stress is generated by the person waiting for the answer.

"To wait would exasperate the French more and more: have we become impatient monsters?" [9].

Waiting to queue in a store, going around the stores to find the dress of your dreams at your size, etc. are stressors that people reveal. It takes time, it wastes time, it forces you to be cold or warm, not to do anything else, to move, to organize yourself to do it.

\section{This requiers patience.}

If we go back in time of our ancestors, a letter taking several days to arrive, a handwritten letter highlighting his education by choosing elaborate words. Today, emoticons mix with onomatopoeias. To go faster. A response is expected just upon receipt of the message.

Not so long ago, when you wanted to redo your wardrobe, you organized a shopping day. This involved finding the time, managing it with transportation according to the choice of location(s) according to needs. Algorithms know your preferences and propose you the clothes of your desires to get them in one click and find or whatever the best price and the right size with an optimized delivery.

The ease of getting almost everything you need in one click in a short period of time and everything changes your behaviour to become impatient.

Why wait in a cold shop after having spent an hour finding a parking space without being sure to find what you are looking for when you can get it from your sofa in one click?

In fact, impatient behaviour develops such as a lack of understanding of not being served quickly, a lack of stock, a different price, etc.

Hello when entering a shop disappears. Buyers rush to the product they are looking for and get annoyed at having to go around the storeif the product is too long to find. Aggressiveness can develop by not getting what you have from the virtual in reality with a single click.

We are looking for an identical service in the real world as the virtual one.

Out of habit of receiving quickly, of obtaining without delay in a daily life, one can develop this form of impatience.

Living in the real world with the help of the virtual world makes it easier to obtain many things quickly and allows you to no longer want to accept a lack of speed. Knowing that reality offers this speed with greater difficulty, there is no compensation to reduce or compensate for this notion of service without constraint obtained quickly over time. 


\section{Conclusion}

The tool connected with which we live in reality changes our behaviour.

My research work on Behavioral Differentiations between the Real and the Virtual is still confirmed on this behavioral modification because of the possibilities offered by the virtual in relation to the real.

One can imagine that a person living in a remote country, used to being served slowly, without having access to everything, living in an environment where everything is accessible and faster than in his remote country, will develop a form of impatience by returning to his origins.

Will he develop the same form of impatience? Would he be more understanding towards the environment of his country of origin? Would it be to make a distinction? Could he go back more easily?

I think that tolerance is possible in this case and less so in the virtual environment. By choice. Because the virtual can only go even more vote and accompany us even more than the real. This is what users expect from it.

The impatience generated by this in reality forces us to question many behaviours in order to integrate them and limit the gap between reality and the virtual.

It would also be preferable for the user of the impatient connected tool to make the distinction between real and virtual.

\section{References}

1. Research Centre for the Study and Observation of Living Conditions: "What has the Internet changed in the way the French buy?", Mélanie ROUSTAN, Franck LEHUEDE, Pascale HEBEL - https://www.credoc.fr/publications/ quest-ce-quinternet-a-change-aux-modes-dachat-desfrancais

2. Laure Belot (2019) "Our time is more and more fragmented": are we more and more impatient, Le Monde.

3. Baromil:

https://lareclame.fr/omd-infographie-baromobile-193803.

4. Jean Cottraux: https://fr.wikipedia.org/wiki/Jean_Cottraux

5. TOUZEAU N (2017) Behavioral Cybercriminals Differentiations between the Real World and the Virtual Space - J Forensic Res 2017 8: 401.

6. TOUZEAU N (2018) Transposition of Modus Operandi from the Real to the Virtual Using Several Signatures: Case of "The Drowned of the Garonne" Serial Crimes in France" - J Forensic Sci \& Criminal Inves 7(5).

7. TOUZEAU N (2018) Avatarization another Way to Understand Cyberbullyers Behavior in the Real and the Virtual Worlds -Forensic Sci Criminol 3(1): 2-2.

8. TOUZEAU N (2018) « Transverse Zone »: Explanation and Definition in Comparison with Comfort Zones - J Forensic Sci \& Criminal - Invest 9(1): 555753.
9. TOUZEAU N (2018) « Virtual Intelligence the Ninth Family of Intelligences to be Added to Howard Gardner's List »Crim Forensic studies 1(1): 180004.

10. TOUZEAU N (2018) "Some behavior differences between bullying and cyber bullying and impacts on adult victims" Crim Forensic studies 1(2): 180008.

11. TOUZEAU N (2018) "Can the Definition of Lying as Known in Real Space be Applied to Lies Perpetuated in the Virtual, Particularly with Regard to the Behavioural Differentiations that Virtual Space Promotes?“ Int J Forens Sci 3(2): 000140.

12. TOUZEAU N (2018) "What Could Be the Concept of Time in Relation to Behavior in the Virtual World?" - COJ Rev \& Res 1(5). - COJRR.000522.2018.

13. Nadine TOUZEAU(2018) "Net-profiling: behavioral analysis of cybercriminals", Amazon editor, Jun 2, 2016. https:// www.amazon.fr/NET-PROFILING-comportementalecybercriminels-Nadine-Touzeau/dp/2955453730

14. LCI NEWS (2018) "Waiting would exasperate the French more and more: have we become impatient monsters?". https://www.lci.fr/psycho/attendre-exaspererait-de-plus-enplus-les-francais-selon-un-sondage-sommes-nous-en-trainde-devenir-des-monstres-d-impatience-2099878.html

Copyright: (C2020 Nadine Touzeau This is an open-access article distributed under the terms of the Creative Commons Attribution License, which permits unrestricted use, distribution, and reproduction in any medium, provided the original author and source are credited. 